\title{
BENTUK NORMAL BIFURKASI HOPF PADA SISTEM UMUM DUA DIMENSI
}

\author{
MELA PUSPITA \\ Program Studi Matematika, \\ Fakultas Matematika dan Ilmu Pengetahuan Alam, Universitas Andalas, \\ Kampus UNAND Limau Manis Padang, Indonesia, \\ email : melapuspita874@gmail.com
}

\begin{abstract}
Abstrak. Pada paper ini dibahas bentuk normal bifurkasi Hopf pada sistem umum dua dimensi. Selanjutnya juga ditunjukkan bahwa sistem umum dua dimensi yang mengalami bifurkasi Hopf dapat ditransformasi ke bentuk normal tersebut.
\end{abstract}

Kata Kunci: Bifurkasi Hopf, bentuk normal, sistem umum dua dimensi

\section{Pendahuluan}

Pada umumnya sistem dinamik yang ditemukan dalam aplikasi matematika tidak hanya bergantung pada variabel, tetapi juga bergantung pada parameter. Biasanya parameter tersebut mempengaruhi perilaku dari sistem. Jika perilaku dari sistem secara kualitatif berbeda pada nilai parameter yang berbeda, maka sistem tersebut dikatakan mengalami gejala bifurkasi. Apabila perubahan perilaku dinamik dari sistem terjadi di sekitar titik ekuilibriumnya, maka bifurkasi tersebut dinamakan bifurkasi lokal. Bifurkasi lokal terdiri dari bifurkasi fold, yang ditandai dengan munculnya nilai eigen nol pada pelinieran sistem, dan bifurkasi Andronof Hopf atau sering disingkat bifurkasi Hopf, yang ditandai dengan munculnya nilai eigen imajiner murni pada pelinieran sistem.

Bifurkasi Hopf dikembangkan pertama kali oleh Eberhard Hopf. Bifurkasi Hopf digunakan untuk menentukan eksistensi solusi periodik (limit cycle) dari suatu sistem. Bifurkas Hopf hanya dapat terjadi pada sistem dinamik yang berdimensi dua atau lebih [3]. Limit cycle sendiri memiliki peranan penting dalam masalah-masalah fisis, karena merepresentasikan fenomena yang terjadi secara berulang, seperti osilasi detak jantung, ayunan bandul, arus listrik, dan lain-lain.

Pada paper ini akan dikaji tentang bentuk normal bifurkasi Hopf, yaitu bentuk yang paling sederhana dari sistem yang mengalami bifurkasi Hopf. Sebarang sistem dua dimensi yang mengalami bifurkasi Hopf dapat ditransformasi ke bentuk normal tersebut. Berdasarkan uraian latar belakang, yang menjadi permasalahan dalam penelitian ini adalah bagaimana menurunkan bentuk normal bifurkasi Hopf pada sistem umum dua dimensi. Pembahasan pada paper ini mengeksplorasi kembali referensi [3]. 


\section{Bentuk Normal Bifurkasi Hopf}

\subsection{Bifurkasi Hopf Superkritikal}

Diberikan sistem dua persamaan diferensial yang bergantung pada satu para-meter berikut :

$$
\begin{aligned}
& \dot{x}_{1}=\alpha x_{1}-x_{2}-x_{1}\left(x_{1}^{2}+x_{2}^{2}\right), \\
& \dot{x}_{2}=x_{1}+\alpha x_{2}-x_{2}\left(x_{1}^{2}+x_{2}^{2}\right),
\end{aligned}
$$

dengan titik ekuilibrium $x_{1}=0$ dan $x_{2}=0$.

Dengan melakukan pelinieran terhadap sistem (2.1) di sekitar titik ekuilibrium, didapatkan matriks Jacobian

$$
A=\left(\begin{array}{cc}
\alpha & -1 \\
1 & \alpha
\end{array}\right),
$$

dengan nilai eigen dari matriks $A$ adalah $\lambda_{1,2}=\alpha \pm i$.

Sistem (2.1) dapat ditulis dalam bentuk variabel kompleks $z=x_{1}+i x_{2}$ sebagai berikut :

$$
\dot{z}=(\alpha+i) z-z|z|^{2} .
$$

Bentuk polar dari sistem (2.1), dengan $z=\rho e^{i \theta}$ dan $\rho \geq 0$ adalah

$$
\dot{\rho}=\rho\left(\alpha-\rho^{2}\right), \quad \dot{\theta}=1 .
$$

Gejala bifurkasi pada sistem (2.1) ketika melewati $\alpha=0$ dapat dianalisis dengan mudah menggunakan bentuk polar (2.3), karena persamaan untuk $\rho$ dan $\theta$ muncul secara terpisah.

Titik ekuilibrium dari persamaan (2.3) diperoleh ketika $\dot{\rho}=0$. Hal ini memberikan

$$
\rho\left(\alpha-\rho^{2}\right)=0 \Longleftrightarrow \rho=0 \text { untuk } \alpha \in \mathbb{R} \text { atau } \rho=\sqrt{\alpha} \text { untuk } \alpha>0 .
$$

Dari hasil di atas dapat disimpulkan bahwa :

(1) Untuk $\alpha \leq 0$, titik ekuilibrium dari (2.3) adalah $\rho=0$.

(2) Untuk $\alpha>0$, titik ekuilibrium dari persamaan (2.3) adalah $\rho=0$ dan $\rho=\sqrt{\alpha}$.

Ketika $t \rightarrow \infty$, maka dari persamaan (2.3) dapat disimpulkan bahwa $\rho \rightarrow 0$ jika $\alpha \leq 0$ dan $\rho \rightarrow \sqrt{\alpha}$ jika $\alpha>0$.

Selanjutnya persamaan $\dot{\theta}$ mendeskripsikan suatu rotasi dengan kecepatan konstan. Karena $\dot{\theta}=1>0$, maka dapat disimpulkan bahwa arah rotasi berlawanan dengan arah jarum jam.

Berdasarkan analisis terhadap persamaan (2.3), diperoleh diagram bifurkasi seperti yang diperlihatkan dalam Gambar 1. Sistem (2.1) selalu mempunyai titik ekuilibrium di $(0,0)$. Titik ekuilibrium ini bertipe spiral stabil jika $\alpha<0$ dan bertipe spiral tak-stabil jika $\alpha>0$. Pada saat $\alpha=0$, titik ekuilibrium $(0,0)$ juga stabil tetapi secara nonlinier, artinya laju kekonvergenan solusi ke titik $(0,0)$ tidak lagi secara eksponensial. Dalam hal ini, $\alpha=0$ disebut titik bifurkasi karena pada titik ini terjadi perubahan kestabilan. 
Selanjutnya untuk $\alpha>0$ juga terdapat limit cycle yang tunggal dan stabil dengan radius $r=\sqrt{\alpha}$. Semua orbit yang dimulai dari luar atau dari dalam cycle, kecuali di titik $(0,0)$, selalu menuju ke cycle ketika $t \rightarrow \infty$, sehingga limit cycle ini dikatakan stabil. Gejala bifurkasi ini dinamakan bifurkasi Andronov-Hopf atau sering disingkat bifurkasi Hopf. Titik $\alpha=0$ disebut titik Hopf karena pada titik inilah muncul bifurkasi Hopf. Bifurkasi Hopf pada sistem (2.1) dikatakan bertipe superkritikal karena limit cycle stabil muncul di sekitar titik ekuilibrium tak-stabil, sehingga disebut bifurkasi Hopf superkritikal.

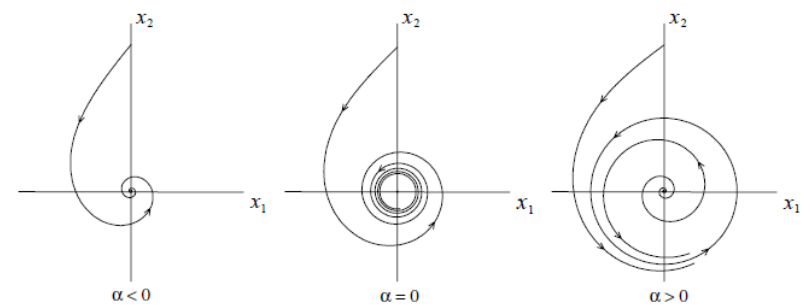

Gambar 1. Bifurkasi Hopf superkritikal

\subsection{Bifurkasi Hopf Subkritikal}

Diberikan sistem dua persamaan diferensial dengan suku nonliniernya berlawanan tanda dengan yang dimiliki sistem (2.1), yaitu

$$
\begin{aligned}
& \dot{x}_{1}=\alpha x_{1}-x_{2}+x_{1}\left(x_{1}^{2}+x_{2}^{2}\right), \\
& \dot{x}_{2}=x_{1}+\alpha x_{2}+x_{2}\left(x_{1}^{2}+x_{2}^{2}\right) .
\end{aligned}
$$

Dalam bentuk kompleks $z=x_{1}+i x_{2}$, sistem (2.4) dapat ditulis menjadi

$$
\dot{z}=(\alpha+i) z+z|z|^{2}
$$

dan bentuk koordinat polar dari sistem (2.4) diberikan oleh persamaan berikut

$$
\dot{\rho}=\rho\left(\alpha+\rho^{2}\right), \quad \dot{\theta}=1 .
$$

Gejala bifurkasi pada sistem (2.4) dapat dianalisis dengan cara yang sama pada sistem (2.1) (Gambar 2). Sistem (2.4) mengalami bifurkasi Hopf pada saat $\alpha=0$. Bertolak belakang dengan sistem (2.1), pada sistem (2.4) terdapat limit cycle takstabil, yang kemudian menghilang ketika $\alpha$ melewati titik nol dari nilai negatif ke nilai positif. Titik ekuilibrium $(0,0)$ memiliki kestabilan yang sama dengan sistem (2.1) untuk $\alpha \neq 0$, yaitu stabil untuk $\alpha<0$ dan tak-stabil untuk $\alpha>0$. Selanjutnya kestabilan sistem (2.4) di titik Hopf berlawanan dengan yang dimiliki sistem (2.1), yaitu tak-stabil (secara nonlinier) di $\alpha=0$. Bifurkasi Hopf pada sistem (2.4) dikatakan bertipe subkritikal karena limit cycle tak-stabil muncul di sekitar titik ekuilibrium stabil, sehingga disebut bifurkasi Hopf subkritikal. 


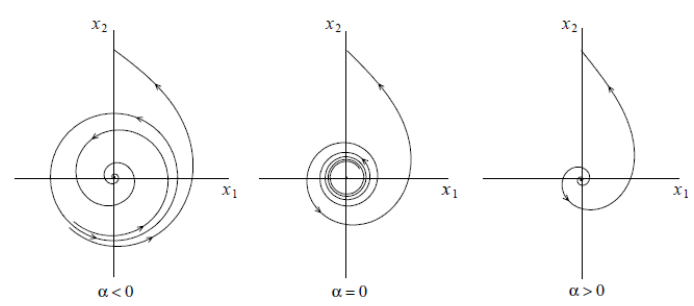

Gambar 2. Bifurkasi Hopf subkritikal

\subsection{Sistem yang ekivalen secara topologi}

Misalkan sistem (2.1) dan (2.4) dapat ditulis kembali dalam bentuk vektor dengan menambahkan suku-suku berorde tinggi sebagai berikut :

$$
\left(\begin{array}{c}
\dot{x}_{1} \\
\dot{x}_{2}
\end{array}\right)=\left(\begin{array}{cc}
\alpha & -1 \\
1 & \alpha
\end{array}\right)\left(\begin{array}{c}
x_{1} \\
x_{2}
\end{array}\right) \pm\left(x_{1}^{2}+x_{2}^{2}\right)\left(\begin{array}{c}
x_{1} \\
x_{2}
\end{array}\right)+\mathcal{O}\left(\|\mathbf{x}\|^{4}\right),
$$

dimana $\mathbf{x}=\left(x_{1}, x_{2}\right)^{T},\|\mathbf{x}\|^{2}=x_{1}^{2}+x_{2}^{2}$, dan suku-suku $\mathcal{O}\left(\|\mathbf{x}\|^{4}\right)$ merupakan fungsi mulus yang bergantung pada $\alpha$. Lema berikut menyatakan bahwa penambahan suku-suku berorde tinggi pada sistem (2.1) dan (2.4) tidak mempengaruhi perilaku bifurkasi Hopf dari sistem tersebut.

Lema 2.1. [3] Sistem (2.7) dengan suku nonlinier bertanda" -" dan" +" berturutturut ekivalen secara topologi di sekitar titik asal terhadap sistem (2.1) dan (2.4).

Berdasarkan Lema 2.1 ini, maka sistem (2.1) dan (2.4) dikatakan sebagai bentuk normal bifurkasi Hopf.

\section{Bifurkasi Hopf Pada Sistem Umum Dua Dimensi}

Pada bagian ini akan dibuktikan bahwa sebarang sistem dua-dimensi yang mengalami bifurkasi Hopf dapat ditransformasi ke bentuk normal (2.1) dan (2.4).

\subsection{Analisis awal}

Diberikan sistem

$$
\dot{\mathbf{x}}=\mathbf{f}(\mathbf{x}, \alpha), \quad \mathbf{x}=\left(x_{1}, x_{2}\right)^{T} \in \mathbb{R}^{2}, \quad \alpha \in \mathbb{R},
$$

dengan $\mathbf{f}$ adalah fungsi mulus bernilai vektor. Misalkan pada saat $\alpha=0$ sistem (3.1) memiliki titik ekuilibrium $\mathbf{x}=\mathbf{0}$ dengan nilai eigen dari matriks Jacobiannya adalah $\lambda_{1,2}= \pm i \omega_{0}, \quad \omega_{0}>0$. Menurut Teorema Fungsi Implisit, sistem tersebut memiliki titik ekuilibrium tunggal $\mathbf{x}_{0}(\alpha)$ pada suatu lingkungan titik asal untuk setiap $|\alpha|$ yang cukup kecil, karena $\lambda=0$ bukan nilai eigen dari matriks Jacobiannya ketika $\alpha=0$. Pergeseran koordinat dapat dilakukan sedemikian sehingga titik ekuilibrium $\mathbf{x}_{0}(\alpha)$ ditempatkan pada titik asal, dengan mengasumsikan tanpa menghilangkan keumuman bahwa $\mathbf{x}=\mathbf{0}$ adalah titik ekuilibrium dari sistem (3.1) untuk $|\alpha|$ yang cukup kecil. Dengan demikian, sistem (3.1) dapat ditulis sebagai

$$
\dot{\mathbf{x}}=A(\alpha) \mathbf{x}+\mathbf{F}(\mathbf{x}, \alpha),
$$


dimana $\mathbf{F}$ adalah suatu fungsi mulus bernilai vektor yang komponen-komponennya, misalkan $F_{1}$ dan $F_{2}$, memiliki ekspansi Taylor dalam $\mathbf{x}$ yang dimulai dengan suku-suku kuadratik, yaitu $\mathbf{F}=\mathcal{O}\left(\|\mathbf{x}\|^{2}\right)$. Matriks Jacobian $A(\alpha)$ dapat ditulis sebagai

$$
A(\alpha)=\left(\begin{array}{ll}
a(\alpha) & b(\alpha) \\
c(\alpha) & d(\alpha)
\end{array}\right)
$$

dengan entri-entrinya adalah fungsi mulus terhadap $\alpha$. Nilai-nilai eigen dari matriks (3.3) adalah akar-akar dari persamaan karakteristik

$$
\lambda^{2}-\sigma(\alpha) \lambda+\Delta(\alpha)=0,
$$

dimana $\sigma(\alpha)=a(\alpha)+d(\alpha)=\operatorname{tr}(A(\alpha))$ dan $\Delta(\alpha)=a(\alpha) d(\alpha)-b(\alpha) c(\alpha)=$ $\operatorname{det}(A(\alpha))$. Jadi

$$
\lambda_{1,2}(\alpha)=\frac{1}{2}\left(\sigma(\alpha) \pm \sqrt{\sigma^{2}(\alpha)-4 \Delta(\alpha)}\right) .
$$

Syarat bifurkasi Hopf mengakibatkan

$$
\sigma(0)=0 \text { dan } \Delta(0)=\omega_{0}^{2}>0 .
$$

Dengan memisalkan

$$
\mu(\alpha)=\frac{1}{2} \sigma(\alpha) \text { dan } \omega(\alpha)=\frac{1}{2} \sqrt{4 \Delta(\alpha)-\sigma^{2}(\alpha)},
$$

maka diperoleh

$$
\lambda_{1}(\alpha)=\lambda(\alpha), \quad \lambda_{2}(\alpha)=\bar{\lambda}(\alpha),
$$

dimana

$$
\lambda(\alpha)=\mu(\alpha)+i \omega(\alpha), \quad \mu(0)=0, \quad \omega(0)=\omega_{0}>0 .
$$

Lema berikut memberikan bentuk kompleks dari sistem (3.2).

Lema 3.1. [3] Sistem (3.2) dengan menggunakan variabel kompleks $z$, untuk $|\alpha|$ yang cukup kecil dapat ditulis sebagai

$$
\dot{z}=\lambda(\alpha) z+g(z, \bar{z}, \alpha),
$$

dimana $g=\mathcal{O}\left(|z|^{2}\right)$ adalah fungsi mulus terhadap $(z, \bar{z}, \alpha)$.

Fungsi $g(z, \bar{z}, \alpha)$ merupakan fungsi analitik di sekitar $z=0$, sehingga dapat ditulis sebagai deret Taylor dalam dua variabel kompleks $z$ dan $\bar{z}$, yaitu

$$
g(z, \bar{z}, \alpha)=\sum_{k+l \geq 2} \frac{1}{k ! l !} g_{k l}(\alpha) z^{k} \bar{z}^{l}
$$

dimana

$$
g_{k l}(\alpha)=\left.\frac{\partial^{k+l}}{\partial z^{k} \partial \bar{z}^{l}}\langle\mathbf{p}(\alpha), F(z \mathbf{q}(\alpha)+\bar{z} \overline{\mathbf{q}}(\alpha))\rangle\right|_{z=0},
$$

untuk $k+l \geq 2$ dengan $k, l=0,1, \ldots$. Misalkan pada saat $\alpha=0$ fungsi $\mathbf{F}(\mathbf{x}, \alpha)$ pada persamaan (3.2) direpresentasikan sebagai

$$
\mathbf{F}(\mathbf{x}, 0)=\frac{1}{2} \mathbf{B}(\mathbf{x}, \mathbf{x})+\frac{1}{6} \mathbf{C}(\mathbf{x}, \mathbf{x}, \mathbf{x})+\mathcal{O}\left(\|\mathbf{x}\|^{4}\right),
$$


dimana entri-entri $\mathbf{B}(\mathbf{x}, \mathbf{y})$ dan $\mathbf{C}(\mathbf{x}, \mathbf{y}, \mathbf{u})$ didefinisikan sebagai

$$
B_{i}(\mathbf{x}, \mathbf{y})=\left.\sum_{j, k=1}^{2} \frac{\partial^{2} F_{i}(\xi, 0)}{\partial \xi_{j} \partial \xi_{k}}\right|_{\xi=0} x_{j} y_{k}, i=1,2,
$$

dan

$$
C_{i}(\mathbf{x}, \mathbf{y}, \mathbf{u})=\left.\sum_{j, k, l=1}^{2} \frac{\partial^{3} F_{i}(\xi, 0)}{\partial \xi_{j} \partial \xi_{k} \partial \xi_{l}}\right|_{\xi=0} x_{j} y_{k} u_{l}, i=1,2
$$

\subsection{Reduksi ke Bentuk Normal}

Pada bagian ini akan dibahas perubahan koordinat nonlinier (kompleks) yang akan menyederhanakan persamaan (3.4) sedemikian sehingga dapat direduksi ke bentuk normal (2.2) dan (2.5). Hal ini dapat dilakukan dengan mengeliminasi semua suku kuadratnya dan suku kubiknya (kecuali suku resonansi). Hasil ini dikenal sebagai bentuk normal Poincareé untuk bifurkasi Hopf, yang diberikan dalam lema berikut.

Lema 3.2. [3] (Bentuk Normal Poincaré untuk Bifurcation Hopf) Persamaan

$$
\dot{z}=\lambda z+\sum_{2 \leq k+l \leq 3} \frac{1}{k ! l !} g_{k l} z^{k} \bar{z}^{l}+\mathcal{O}\left(|z|^{4}\right),
$$

dimana $\lambda \equiv \lambda(\alpha)=\mu(\alpha)+i \omega(\alpha)$, dengan $\mu(0)=0$ dan $\omega(0)=\omega_{0}>0$, dan $g_{i j} \equiv$ $g_{i j}(\alpha)$, dapat ditransformasi oleh perubahan koordinat kompleks yang invertibel,

$$
z=w+\frac{h_{20}}{2} w^{2}+h_{11} w \bar{w}+\frac{h_{02}}{2} \bar{w}^{2}+\frac{h_{30}}{6} w^{3}+\frac{h_{12}}{2} w \bar{w}^{2}+\frac{h_{03}}{6} \bar{w}^{3},
$$

untuk $|\alpha|$ yang cukup kecil, menjadi persamaan yang hanya memuat satu suku kubik resonansi, yaitu

$$
\dot{w}=\lambda w+c_{1} w^{2} \bar{w}+\mathcal{O}\left(|w|^{4}\right)
$$

dimana $c_{1} \equiv c_{1}(\alpha)$

Selanjutnya bentuk normal Poincaré ditransformasi menjadi bentuk normal yang telah dibahas pada bab sebelumnya. Hasilnya diberikan dalam Lema berikut.

Lema 3.3. [3] Diberikan persamaan

$$
\frac{d w}{d t}=(\mu(\alpha)+i \omega(\alpha)) w+c_{1}(\alpha) w|w|^{2}+\mathcal{O}\left(|w|^{4}\right)
$$

$\operatorname{dimana} \mu(0)=0$ dan $\omega(0)=\omega_{0}>0$.

Misalkan $\mu^{\prime}(0) \neq 0$ dan $\operatorname{Re}\left(c_{1}(0)\right) \neq 0$. Dengan menggunakan suatu transformasi koordinat kompleks, rescaling waktu, dan reparameterisasi waktu, maka persamaan (3.7) dapat direduksi menjadi

$$
\frac{d u}{d \gamma}=(\beta+i) u+s u|u|^{2}+\mathcal{O}\left(|u|^{4}\right),
$$


dimana $u$ adalah koordinat kompleks yang baru, $\gamma$ dan $\beta$ masing-masing adalah waktu dan parameter yang baru, dan $s=\operatorname{sign}\left(\operatorname{Re}\left(c_{1}(0)\right)\right)= \pm 1$.

\section{Bukti.}

\section{Langkah ke-1 (Scaling waktu linier)}

Misalkan $\tau=\omega(\alpha) t$ sebagai parameter waktu yang baru. Dalam hal ini, arah waktu tidak berubah karena $\omega(\alpha)>0$ untuk $|\alpha|$ yang cukup kecil. Maka

$$
\frac{d w}{d \tau}=\frac{d w}{d t} \frac{d t}{d \tau}=\left[\frac{\mu(\alpha)}{\omega(\alpha)}+i\right] w+\frac{c_{1}(\alpha)}{\omega(\alpha)} w|w|^{2}+\mathcal{O}\left(|w|^{4}\right) .
$$

Dengan memisalkan

$$
\beta=\beta(\alpha)=\frac{\mu(\alpha)}{\omega(\alpha)}, \quad d_{1}(\beta)=\frac{c_{1}(\alpha(\beta))}{\omega(\alpha(\beta))},
$$

maka persamaan terakhir dapat ditulis

$$
(\beta+i) w+d_{1}(\beta) w|w|^{2}+\mathcal{O}\left(|w|^{4}\right) .
$$

$\beta$ dapat dipandang sebagai parameter baru karena

$$
\beta(0)=0, \quad \beta^{\prime}(0)=\frac{\mu^{\prime}(0)}{\omega(0)} \neq 0,
$$

sehingga Teorema Fungsi Invers menjamin eksistensi lokal dan kemulusan dari $\alpha$ sebagai fungsi terhadap $\beta$.

\section{Langkah ke-2 (Reparameterisasi waktu nonlinier)}

Misalkan parameter waktu yang baru $\gamma=\gamma(\tau, \beta)$, dimana

$$
d \gamma=\left(1+e_{1}(\beta)|w|^{2}\right) d \tau,
$$

dengan $e_{1}(\beta)=\operatorname{Im}\left(d_{1}(\beta)\right)$. Perubahan waktu tersebut adalah suatu transformasi near-identity di sekitar titik asal. Dengan menggunakan reparameterisasi waktu yang baru ini diperoleh

$$
\frac{d w}{d \gamma}=\frac{d w}{d \tau} \frac{d \tau}{d \gamma}=(\beta+i) w+w|w|^{2}\left[\operatorname{Re}\left(d_{1}(\beta)\right)-\beta e_{1}(\beta)\right]+\mathcal{O}\left(|w|^{4}\right) .
$$

Misalkan

$$
l_{1}(\beta)=\operatorname{Re}\left(d_{1}(\beta)\right)-\beta e_{1}(\beta),
$$

maka jelas $l_{1}(\beta)$ adalah riil dan

$$
l_{1}(0)=\operatorname{Re}\left(d_{1}(0)\right)=\frac{\operatorname{Re}\left(c_{1}(0)\right.}{\omega(0)} .
$$

\section{Langkah ke-3 (Scaling koordinat linier)}

Misalkan variabel kompleks baru $u$ dimana berlaku

$$
w=\frac{u}{\sqrt{\left|l_{1}(\beta)\right|}} .
$$


Karena $\operatorname{Re}\left(c_{1}(0)\right) \neq 0$, maka $l_{1}(0) \neq 0$. Akibatnya penyebut pada persamaan (3.9) tidak pernah nol. Dengan menggunakan variabel kompleks yang baru ini diperoleh

$$
\frac{d u}{d \gamma}=(\beta+i) u \frac{l_{1}(\beta)}{+}\left|l_{1}(\beta)\right| u|u|^{2}+\mathcal{O}\left(|u|^{4}\right)
$$

dimana $\frac{l_{1}(\beta)}{\left|l_{1}(\beta)\right|}= \pm 1$ untuk setiap $\beta$. Dengan demikian persamaan (3.10) dapat ditulis menjadi

$$
\frac{d u}{d \gamma}=(\beta+i) u+s u|u|^{2}+\mathcal{O}\left(|u|^{4}\right),
$$

dimana $s=\operatorname{sign}\left(l_{1}(0)\right)=\operatorname{sign}\left(\operatorname{Re}\left(c_{1}(0)\right)\right)$.

Definisi berikut memberikan istilah untuk fungsi riil $l_{1}(\beta)$.

Definisi 3.4. [3] Fungsi riil $l_{1}(\beta)$ yang diberikan oleh persamaan (3.8) disebut koefisien pertama Lyapunov.

Berdasarkan (3.9), koefisien pertama Lyapunov saat $\beta=0$ dapat dihitung dengan

$$
l_{1}(0)=\frac{1}{2 \omega_{0}^{2}} \operatorname{Re}\left(i g_{20} g_{11}+\omega_{0} g_{21}\right)
$$

Dengan demikian, kita hanya perlu menentukan turunan ketiga dan kedua sisi kanan pada persamaan (3.11) di titik bifurkasi untuk menghitung $l_{1}(0)$. Nilai dari $l_{1}(0)$ tergantung pada penormalan dari vektor eigen $\mathbf{q}$ dan $\mathbf{p}$, sedangkan sign-nya invarian terhadap scaling $\mathbf{q}, \mathbf{p}$ yang memenuhi penormalan $\langle\mathbf{p}, \mathbf{q}\rangle=1$. Persamaan pada $u$ dengan $s=-1$ yang ditulis dalam bentuk riil sama dengan sistem (2.7). Hasil yang diperoleh ini disimpulkan dalam teorema berikut.

Teorema 3.5. [3] Diberikan sistem dua dimensi berikut ini :

$$
\frac{d \mathbf{x}}{d t}=\mathbf{f}(\mathbf{x}, \alpha), \quad \mathbf{x} \in \mathbb{R}^{2}, \alpha \in \mathbb{R},
$$

dengan $\mathbf{f}$ fungsi mulus, mempunyai titik ekuilibrium $\mathbf{x}=\mathbf{0}$ untuk $|\alpha|$ yang cukup kecil dengan nilai eigen

$$
\lambda_{1,2}=\mu(\alpha) \pm i \omega(\alpha),
$$

$\operatorname{dimana} \mu(0)=0$ dan $\omega(0)=\omega_{0}>0$.

Misalkan kedua syarat berikut terpenuhi :

(B.1) $l_{1}(0) \neq 0$, dimana $l_{1}$ adalah koefisien pertama Lyapunov, (B.2) $\mu^{\prime}(0) \neq 0$.

Maka terdapat suatu perubahan parameter dan koordinat yang invertibel serta suatu reparameterisasi waktu yang mentransformasi sistem (3.12) menjadi

$$
\frac{d}{d \tau}\left(\begin{array}{l}
y_{1} \\
y_{2}
\end{array}\right)=\left(\begin{array}{cc}
\beta & -1 \\
1 & \beta
\end{array}\right)\left(\begin{array}{l}
y_{1} \\
y_{2}
\end{array}\right) \pm\left(y_{1}^{2}+y_{2}^{2}\right)\left(\begin{array}{l}
y_{1} \\
y_{2}
\end{array}\right)+\mathcal{O}\left(\|\mathbf{y}\|^{4}\right) .
$$


Dengan menggunakan Lema 2.1, suku $\mathcal{O}\left(\|\mathbf{y}\|^{4}\right)$ dapat dieliminasi dan akhirnya menghasilkan teorema utama berikut.

Teorema 3.6. [3] (Bentuk normal topologi untuk bifurkasi Hopf) Sebarang sistem umum dua dimensi dengan satu parameter,

$$
\dot{\mathbf{x}}=\mathbf{f}(\mathbf{x}, \alpha),
$$

yang memiliki titik ekuilibrium $\mathbf{x}=\mathbf{0}$ pada saat $\alpha=0$ dengan nilai eigen

$$
\lambda_{1,2}(0)= \pm i \omega_{0}, \omega_{0}>0,
$$

adalah ekivalen secara topologi di sekitar titik asal ke salah satu bentuk normal berikut:

$$
\left(\begin{array}{l}
\dot{y_{1}} \\
\dot{y_{2}}
\end{array}\right)=\left(\begin{array}{cc}
\beta & -1 \\
1 & \beta
\end{array}\right)\left(\begin{array}{l}
y_{1} \\
y_{2}
\end{array}\right) \pm\left(y_{1}^{2}+y_{2}^{2}\right)\left(\begin{array}{l}
y_{1} \\
y_{2}
\end{array}\right) \text {. }
$$

\section{Kesimpulan}

Pada paper ini telah dibahas bentuk normal bifurkasi Hopf pada sistem dua dimensi, yang diberikan oleh

$$
\left(\begin{array}{c}
\dot{x}_{1} \\
\dot{x}_{2}
\end{array}\right)=\left(\begin{array}{cc}
\alpha & -1 \\
1 & \alpha
\end{array}\right)\left(\begin{array}{l}
x_{1} \\
x_{2}
\end{array}\right) \pm\left(x_{1}^{2}+x_{2}^{2}\right)\left(\begin{array}{c}
x_{1} \\
x_{2}
\end{array}\right) .
$$

Tanda "+" pada suku nonlinier menyatakan sistem mengalami bifurkasi Hopf subkritikal, sedangkan tanda " -" menyatakan sistem mengalami bifurkasi Hopf superkritikal. Selanjutnya pada paper ini juga sudah ditunjukkan bahwa sistem umum dua dimensi yang mengalami bifurkasi Hopf dapat ditransformasi ke bentuk normal (4.1).

\section{Ucapan Terima kasih}

Penulis mengucapkan terima kasih kepada Bapak Dr. Mahdhivan Syafwan, Ibu Monika Rianti Helmi M.Si, Bapak Prof. Syafrizal Sy, Bapak Zulakmal, M.Si dan Bapak Dr. Dodi Devianto yang telah memberikan masukan dan saran sehingga paper ini dapat diselesaikan dengan baik.

\section{Daftar Pustaka}

[1] Boyce, W.E and R.C. DiPrima. 2001. Elementary Differential Equations and Boundary Value Problems. John Wiley and Sons, New York

[2] Kirwan, F. 1992. Complex Algebraic Curves. Cambridge University Press, Cambridge

[3] Kuznetsov, Y.A. 1998. Elements of Applied Bifurcation Theory Second Edition. Springer, New York

[4] Lynch, S. 2007. Dynamical Systems with Aplications using mathematica. Birkhauser, Boston 